\title{
Patent Omphalomesenteric Duct with Protruding Bowels through a Ruptured Omphalocele
}

\author{
Emil Mammadov
}

Department of Pediatric Surgery, Near East University School of Medicine, Nicosia, Cyprus

Persistent omphalomesenteric duct is a rare congenital anomaly and protrusion of the bowel through the duct is the only neonatal emergent clinical entity associated with this condition. The pathogenesis is the lack of intestinal involution by the ninth gestational week. There are several associated anomalies like intestinal malrotation, oesophageal atresia and omphalocele, which are all extremely rare (1-5). Herein, we present our case of successful surgical correction of this anomaly.

A male baby was delivered by $\mathrm{C} / \mathrm{S}$ in the $32^{\text {nd }}$ gestational week due to foetal distress. Upon newborn examination, a bowel segment protruding from the caudal portion of a small omphalocele was detected. The distal part of the bowel seemed to be in a state of vascular compromise (red arrow, Figure 1). The anomaly initially looked like a ruptured omphalocele. Total

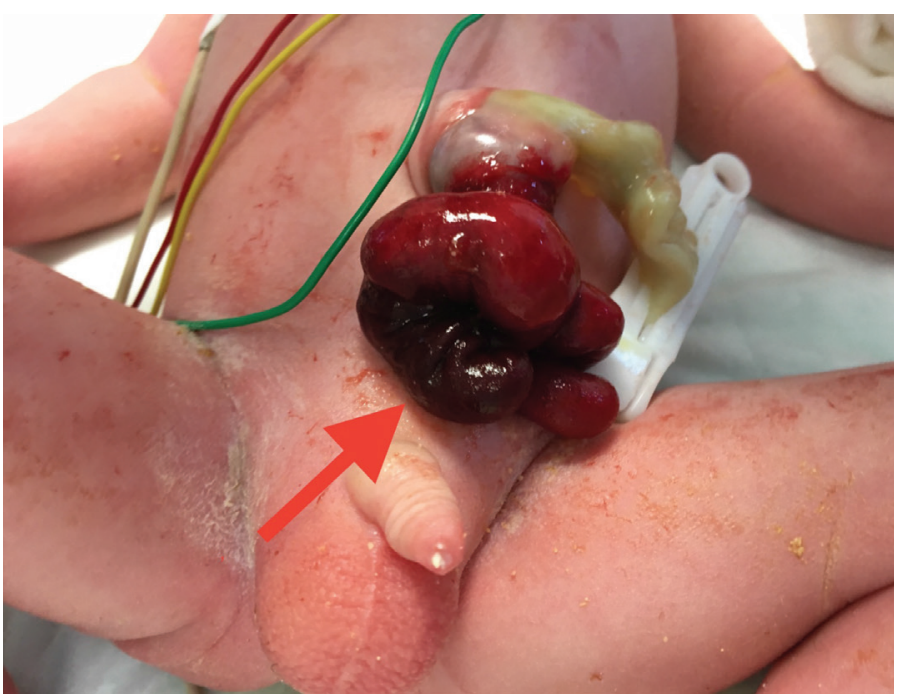

FIG. 1. Bowel segments protruding from caudal portion of a small omphalocele. Distal part of the protruded bowel is compromised (red arrow). blood count, biochemistry and abdominal ultrasonography were normal. Pulmonary hypertension was detected by echocardiography. Informed consent was obtained from the family. Emergent exploration was performed through the caudal portion of the omphalocele. Patent omphalomesenteric duct (yellow arrow, Figure 2) with prolapse of both proximal and distal segments of adjacent terminal ileum were noted. The bowel was reduced; resection of the patent omphalomesenteric duct and adjacent bowel with anastomosis and umbilicoplasty (Figure 3) was performed. Bowel exploration showed no

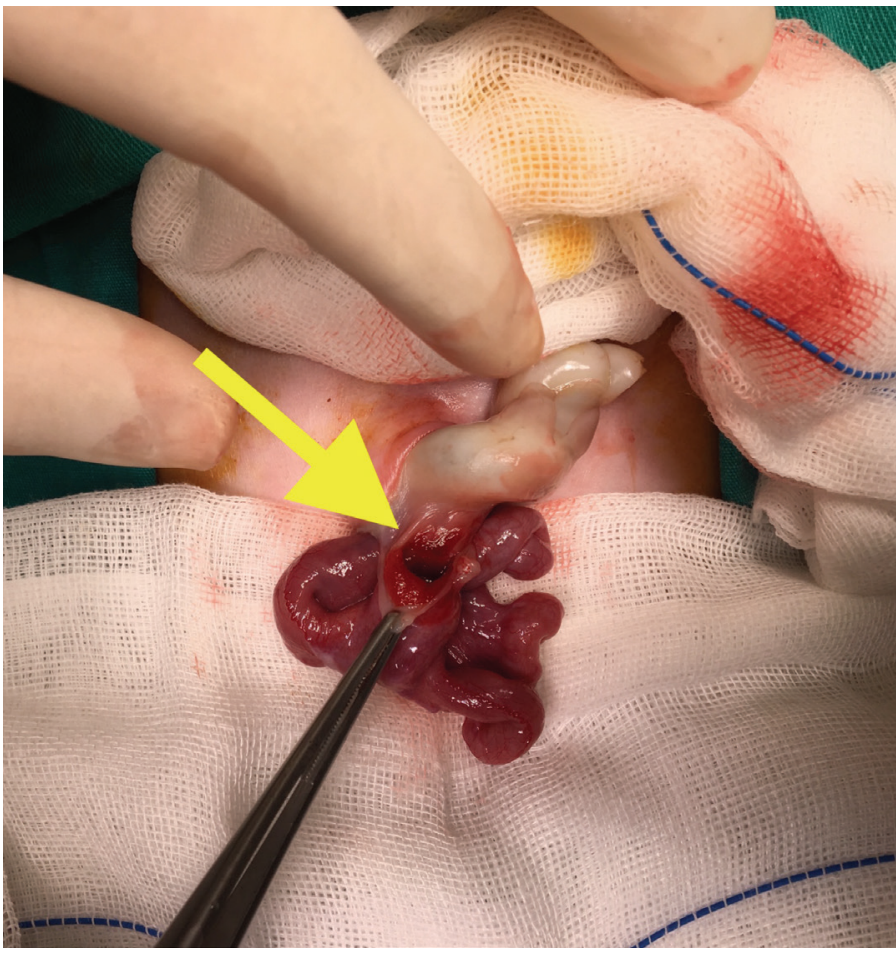

FIG. 2. Patent omphalomesenteric duct (yellow arrow) upon exploration.

Address for Correspondence: Dr. Emil Mammadov, Department of Pediatric Surgery, Near East University School of Medicine, Nicosia, Cyprus Phone: +905338496905 e-mail: dremilmammadov@gmail.com - emil.mammadov@neu.edu.tr ORCID ID: orcid.org/0000-0001-8143-1643 Received: 16 February 2017 Accepted: 10 August 2017•DOI: 10.4274/balkanmedj.2017.0230

Available at www.balkanmedicaljournal.org

Cite this article as:

Mammadov E. Patent Omphalomesenteric Duct with Protruding Bowels through a Ruptured Omphalocele. Balkan Med J 2018;35:118-9

${ }^{\circ}$ Copyright 2018 by Trakya University Faculty of Medicine / The Balkan Medical Journal published by Galenos Publishing House 


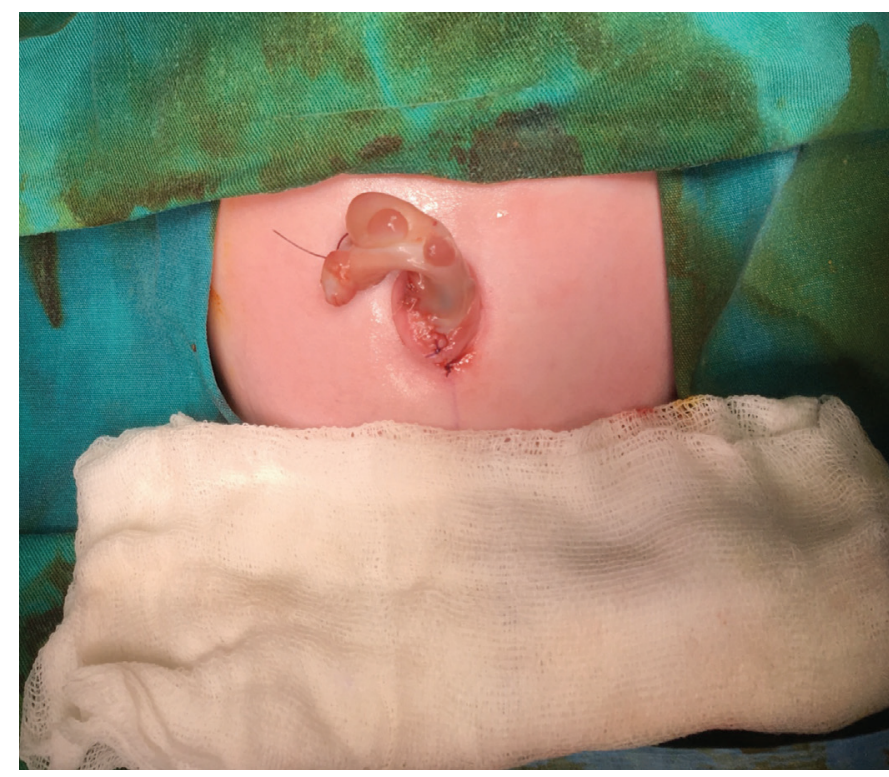

FIG. 3. Completed umbilicoplasty view. additional gastrointestinal pathology. Enteral feeding was initiated on the second postoperative day and the surgical course was uneventful. After completion of the treatment for pulmonary hypertension, the baby was discharged from the hospital on the $15^{\text {th }}$ day. Pathologic examination of the excised specimen showed eroded and congested columnar epithelium without any sign of ectopic mucosa.

\section{REFERENCES}

1. Saad DF, Gow KW. Images in clinical medicine. Small-bowel prolapse through a persistent omphalomesenteric duct. N Engl J Med 2005;353:e1.

2. Aziz Khan Y, Qureshi MA, Akhtar J. Omphalomesenteric duct cyst in an omphalocele: a rare association. Pak J Med Sci 2013;29:866-8.

3. Panait N, Michel F, D'Ercole C, Merrot T. Esophageal atresia, small omphalocele and ileal prolapse through a patent omphalomesenteric duct: a methimazole embryopathy? [Corrected]. J Pediatr Surg 2013;48:E9-11.

4. Periquito IR, Marques T, Lima S, Ferreira M. Patent omphalomesenteric duct: sectioning the unexpected. BMJ Case Rep 2014:2014.

5. Bagade S, Khanna G. Imaging of omphalomesenteric duct remnants and related pathologies in children. Curr Probl Diagn Radiol 2015;44:246-55. 